\title{
O PROFISSIONAL CONTÁBIL E AS NOVAS TECNOLOGIAS
}

\section{ARTIGO ORIGINAL}

HACKBAHTH, lara Carla Nonato Souza ${ }^{1}$

HACKBAHTH, lara Carla Nonato Souza. O profissional contábil e as novas tecnologias. Revista Científica Multidisciplinar Núcleo do Conhecimento. Ano 05, Ed. 11, Vol. 07, pp. 98-103. Novembro de 2020. ISSN: 2448-0959, Link de acesso:https://www.nucleodoconhecimento.com.br/contabilidade/novas-tecnologias

\section{RESUMO}

Os avanços tecnológicos têm sido um dos fatores que influenciam a forma como as organizações irão investir seus ativos e traçar seu planejamento estratégico. Nesse sentido os profissionais de contabilidade para estarem em uma posição estratégica apoiando os planos dessas organizações, devem acompanhar os avanços tecnológicos que influenciam diretamente as organizações no âmbito financeiro e contábil, e indiretamente, as tecnologias que afetem todos os níveis das organizações. A pesquisa tem como objetivo fazer um estudo sobre a atuação do profissional contábil diante das novas tecnologias e sua atuação na geração de informações para a tomada de decisão. A pesquisa foi exploratória e descritiva, e a coleta de dados foi por meio de fontes secundárias, envolvendo trabalhos acadêmicos publicados em periódicos nacionais, teses e dissertações. Quanto aos resultados da pesquisa foram todos alcançados, chegando-se à conclusão de que o profissional contábil tem papel importante no contexto e que deve estar atualizado às novas tecnologias para que possam fornecer informações mais seguras e confiáveis a diretoria das empresas, auxiliando-os no processo de tomada de decisões.

1 Bacharel em Ciências Contábeis, Pós Graduada em Controladoria Finanças e Compliance, Pós Graduada em Liderança e Coaching, Pós Graduada em Auditoria, Contabilidade e Perícia. 
Palavras-Chave: Profissional contábil, desafios da profissão, tecnologias.

\section{INTRODUÇÃO}

Diante do novo cenário moldado por empresas de capital estrangeiro o Brasil tem vivenciado o avanço acelerado de novas tecnologias, o que torna essencial para as empresas nacionais a busca por mais qualidade da sua produtividade tornando-as mais competitivas no mercado externo. Esses avanços tecnológicos influenciam diretamente os profissionais da contabilidade que estão atentos as novas exigências do mercado, sendo eles alguns dos profissionais que mais utilizam essas tecnologias o que os coloca em uma posição de busca constante por atualização, tornando os profissionais essenciais dentro das organizações.

O desafio é cada vez maior para os profissionais contábeis que precisam aprimorar a capacidade técnica a constante atualização e só assim conseguirão ter sucesso no desempenho de suas atividades. O desafio é estar conectado com todas as mudanças inerentes aos processos do cotidiano, assim como na tecnologia da informação mundial levando em conta a Internacionalização das Regras de Contabilidade não é suficiente a atualização a nível de Brasil e sim do mundo o que proporciona novas tendências para os profissionais da área.

\section{A FINALIDADE DA CONTABILIDADE}

De acordo com ludícibus (2000, p. 22), a Contabilidade tem como propósito controlar fenômenos que ocorrem em patrimônios de uma determinada entidade, por meio de registros, classificação, demonstração expositiva, análise e interpretação dos fatos ocorridos nestes locais, "objetivando fornecer informações e orientações necessárias à tomada de decisões sobre sua composição e variações, bem como sobre o resultado econômico decorrente da gestão da riqueza patrimonial".

Atualmente além das principais finalidades da Contabilidade exige-se muito mais dos profissionais, pois esses profissionais precisam ser extremamente tecnológicos tendo 
capacidade e habilidades suficientes para resolver problemas, propor soluções e ser detentor de conhecimento de tecnologias e seus impactos dentro das organizações.

\section{O NOVO PERFIL DO PROFISSIONAL CONTÁBIL}

O Brasil é a oitava economia do mundo uma posição importante no ranking internacional mas além da sua posição econômica temos outro tema igualmente importante para os profissionais da contabilidade o IFRS que significa um conjunto de normas internacionais de contabilidade revisadas e emitidas pelo International Accounting Standards Board - IASB (Conselho de Normas Internacionais de Contabilidade) esse cenário em que os profissionais da contabilidade estão inseridos os colocam diante do grande desafio talvez o maior de todos, saber de sua importância nos cenários econômico e social além de ter consciência de que jamais poderão deixar de buscar a renovação, capacitação e, porque não tornar um cientista para superar desafios mercado.

O profissional contábil precisa ser visto como um comunicador de informações essenciais à tomada de decisões, pois a habilidade em avaliar fatos passados, perceber os presentes e predizer eventos futuros pode ser compreendido como fator preponderante ao sucesso empresarial. (SILVA, 2003, p. 3)

Não cabe mais a visão antiquada de o contador um funcionário indireto do governo, cuja principal atividade era calcular impostos e preencher guias e formulários para atender o fisco. Nesse contexto, o profissional contábil deverá mostrar que o seu papel se tornou ainda mais importante nos aspectos econômicos e sociais, embora a informatização e automação tenham substituído o ser humano em alguns aspectos, sendo capaz de interpretar os números e tomar decisões a todo tempo em prol do requerimento por parte do cientista do patrimônio, com conhecimentos científicos requeridos por um profissional comprometido com o seu ofício.

\section{TECNOLOGIA DE INFORMAÇÃO NA CONTABILIDADE}

As vantagens de poder contar com os avanços tecnológicos que evoluem a todo momento são incontáveis, mas a principal para a Contabilidade sem dúvidas é a 
possibilidade de gerar informações em um espaço de tempo extremamente curto e com mínima margem de erros.

Os gestores estão cada vez mais focados em fornecer informações com qualidade e em curto espaço de tempo assegurando a tomada de decisão de forma eficaz, o que leva os profissionais da $\mathrm{TI}$ a aperfeiçoarem de forma constate os mecanismos e processos adequando-os as necessidades de cada seguimento empresarial. Cruz (1998, p. 20) assim a conceitua: "Tecnologia da Informação é todo e qualquer dispositivo que tenha capacidade para tratar dados e/ou informações, tanto de forma sistêmica como esporádica, quer esteja aplicada no produto, quer no processo".

Considerando a definição do autor, vale ressaltar que essa ferramenta representa competitividade e uma influência decisiva, levando se em conta que atinge a forma como as companhias atuam, operacionalizam seus processos e concorrem entre si. De forma definitiva o uso da tecnologia da informação deixou de ser uma preocupação técnica e passou a ser uma questão estratégica, sendo responsável por grande parte do sucesso das organizações.

Não diferente dos demais seguimentos empresariais a Contabilidade precisava de uma mudança nos meios como era executada; operacionalizando seus processos e se atualizando tecnologicamente, sendo assim o profissional contábil deve estar conectado as atualizações com os recursos tecnológicos existentes no mercado. Uma das principais se não a mais importante é o ERP (Enterprise Resource Planning), que em português significa; planejamento dos Recursos da Empresa, atuando como um sistema integrado de gestão. Pode-se compreender que o software de gestão é um sistema que atenta a todas as operações cotidianas de uma empresa, sejam elas o Faturamento, o Balanço Patrimonial, de Compras a Fluxo de Faixa, Recursos Humanos, Finanças, geração de Nota Fiscal, de Apuração de Impostos a Administração de Pessoal, de Inventário de Estoque às Contas a Receber, do Ponto dos Funcionários a controle do maquinário da fábrica, entre outros trabalhos administrativos e operacionais realizados em uma empresa.

\section{CONSIDERAÇÕES FINAIS}


A contabilidade quando atua de forma consultiva pode ser entendida como uma ferramenta que ajuda na resolução de questões gerenciais da empresa, se baseando nos resultados contábeis. Essa atuação tem sido o diferencial para os profissionais da área e os avanços da tecnologia impulsionam e tornam possível proporcionar a sociedade empresarial informações cada vez mais rápidas e precisas levando as empresas a buscarem soluções mais eficazes possibilitando agilizar as tomadas de decisões. Neste artigo, apontamos como uma das soluções o Sistema Integrado de Gestão (ERP), que possibilita analisar a empresa como um sistema coeso, repleto de interações.

A mudança do perfil profissional do contador, que antes era apenas a pessoa responsável pela escrituração dos fatos que alterem o patrimônio das empresas para um gestor efetivo com o papel de auxiliar nas tomadas de decisões, pode ser facilitada com a implantação dos Sistemas Integrados (ERPs), uma vez que o sistema será responsável pela parte operacional dos registros, enquanto o profissional de Contabilidade pela análise dos mesmos.

\section{REFERÊNCIAS}

ALBERTÃO, S. E. ERP-Sistemas de Gestão Empresarial: metodologia para avaliação, seleção e implantação para pequenas e médias empresas. São Paulo: Iglu, 2001.

CRUZ, T. Sistemas de Informações Gerenciais. São Paulo: Atlas, 1998.

. Entenda o que é ERP (Sistemas de Gestão Empresarial). Portal ERP, 30/01/2012. Disponível em: https://portalerp.com/entenda-erp

CFC- Conselho Federal De Contabilidade, 03/10/2018. Disponível em: https://cfc.org.br/noticias/a-importancia-dos-normatizadores-nacionais-para-odesenvolvimento-dos-ifrs/

IUDÍCIBUS, S. Teoria da contabilidade. 6. ed. São Paulo: Atlas, 2000. 
SOUZA, E.; ASCENÇÃO, H.; SOUZA, I. Adequação Do Profissional De Contabilidade Junto As Novas Tecnologias Dos Sistemas Integrados De Informação. Brasil Escola.

https://meuartigo.brasilescola.uol.com.br/informatica/adequacao-profissionalcontabilidade-junto-as-novas-.htm

Enviado: Junho, 2020.

Aprovado: Novembro, 2020. 